\title{
VULNERABILIDADE E INVISIBILIDADE: UM ESTUDO COM CONSUMIDORES COM SÍNDROME DE DOWN
}

\author{
VULNERABILITY AND INVISIBILITY: A STUDY WITH CONSUMERS WITH DOWN SYNDROME
}

\section{Marina Dias de Faria}

Professora Adjunta da Universidade Federal do Estado do Rio de Janeiro, Rio de Janeiro (RJ), Brasil

\section{Leticia Casotti}

Professora Adjunta da Universidade Federal do Rio de Janeiro, Rio de Janeiro (RJ), Brasil

\section{José Luis Carvalho}

Professor Associado da Universidade Federal do Rio de Janeiro, Rio de Janeiro (RJ), Brasil

\section{RESUMO}

Em resposta a demandas por pesquisa com foco na vulnerabilidade de pessoas com deficiência e consumidoras, esta pesquisa estipulou o objetivo de compreender como se revela a vulnerabilidade do consumidor com síndrome de Down em suas interações com o ambiente de mercado da cidade do Rio de Janeiro. Na etapa empírica do estudo, foram conduzidas entrevistas semiestruturadas em profundidade com dezoito sujeitos Down e com seus familiares, num total de 44 informantes. A coleta de dados escorou-se em narrativas de histórias de vida, descrição de fotografias e aplicação de técnicas projetivas. Tratados por análise de conteúdo, os dados geraram quatro categorias, sendo a primeira relacionada à mobilidade urbana, a segunda ao ambiente sociotécnico do mercado, a terceira aos problemas envolvendo dinheiro e crédito e, finalmente, a quarta à invisibilidade do consumidor com síndrome de Down.

Palavras-chave: Vulnerabilidade do consumidor; exclusão; síndrome de Down.

\section{ABSTRACT}

In response to demands for research focusing on the vulnerability of people with disabilities who are consumers, this research has set the objective of understanding how is the consumer with Down syndrome vulnerability revealed in their interactions with the market environment of Rio de Janeiro city. In the empirical part of the study, semi-structured in-depth interviews have been conducted with eighteen Down subjects and with their relatives, in a total of 44 informants. Data collection has been anchored in narratives of life stories, photographs description, and application of projective techniques. Treated by content analysis, the data generated four categories: the first is related to urban mobility, the second to the socio-technical environment of the market, the third to problems involving money and credit, and finally the fourth to the consumer with Down syndrome invisibility.

Keywords: Consumer vulnerability; exclusion; Down syndrome. 


\section{INTRODUÇÃO}

No campo acadêmico de marketing, subsiste o reconhecimento de que interagir com o mercado pode exercer um papel positivo nas vidas e nas identidades dos consumidores. Contudo, para Baker, Gentry e Rittenburg (2005), Shultz e Holbrook (2009) e Mason e Baker (2014), entre outros pesquisadores, o que não se costuma reconhecer é a instabilidade individual, a precariedade social e o desfavorecimento relacionados à falta de acesso e a problemas de aceitação dos consumidores pelo mercado. Assim, os ambientes de consumo podem ser abarcados como locais de significação e conexão, mas também podem se afigurar como fontes de exclusão, desigualdades e conflitos psicossociais.

Hamilton, Dunnett e Piacentini (2015) definem a vulnerabilidade do consumidor como um estado indesejável catalisado por condições variadas que afetam o modo como indivíduos experimentam, interpretam e reagem ao mercado, bem como a maneira pela qual o mercado responde a eles. Tal estado pode ser transitório - como para o caso da perda de emprego, de desastre natural ou de doença -, mas também pode se configurar de forma permanente, como ocorre com idosos e pessoas que apresentam certas deficiências físicas, sensórias e/ou intelectuais. As autoras sobrelevam que a noção de vulnerabilidade vem sendo operacionalizada como um rótulo atribuído a grupos ou indivíduos dentro da sociedade, mas que a ideia de um consumidor vulnerável deve ser articulada sob uma perspectiva crítica, simultaneamente a partir de uma ordenação circunstancial e de uma construção sociocultural, por meio da qual indivíduos são destituídos de poder diante do mercado.

Destacando que a vulnerabilidade do consumidor normalmente adquire características específicas que diferem de um contexto para outro, Shultz e Holbrook (2009) defendem que pesquisas acerca de aspectos, dimensões e frequências dos problemas relativos à vulnerabilidade no consumo são necessárias, especialmente com respeito às particularidades de tais problemas em diversas partes do planeta.

Hilhorst e Bankoff (2004) arrazoam que a própria natureza do conceito desafia a possibilidade de perquirir a vulnerabilidade sob uma ótica geral, apontando para a premência de realizar sondagens locais ou regionais, bem como para análises dinâmicas sobre aquilo que torna um indivíduo vulnerável e acerca dos processos por meio dos quais ele se torna resiliente. Circunscreve-se então o escopo desta pesquisa ao Rio de Janeiro, município detentor do epíteto de "Cidade Maravilhosa", agraciado em 2012 pela Organização das Nações Unidas para a Educação, Ciência e Cultura (Unesco) com o título de Patrimônio Cultural da Humanidade (NOVAIS, 2014), que Ihe vale a reputação de um dos mais importantes polos de atração turística do mundo (ROCHA; ZOUAIN, 2015), mas que, paradoxalmente, apresenta graves problemas estruturais inclusive no que se refere à oferta e ao consumo de bens e serviços -, os quais impedem que seus cidadãos tenham a qualidade de vida que se espera em uma cidade globalmente festejada (FARIA; SILVA; FERREIRA, 2012). Vale recordar que, pelos dados do último censo do Instituto Brasileiro de Geografia e Estatística (IBGE, 2010), no Rio de Janeiro residem 9\% dos 45 milhões de brasileiros com deficiências.

Em paralelo, Elms e Tinson (2012) argumentam que remanesce a demanda acadêmica por investigações qualitativas que perscrutem os comportamentos de consumidores com deficiências em face da sua vulnerabilidade no mercado, visto que tais comportamentos se esteiam de maneira idiossincrática. A pesquisa dirige, portanto, sua atenção para as pessoas com deficiências ( $P C D)$, um agrupamento tão vasto quanto podem ser profusos os problemas facejados por tais indivíduos em relação à vulnerabilidade. Por exemplo, no Brasil, Damascena (2014, p. 14) explorou a vulnerabilidade de consumidores com deficiência visual em supermercados e 
sugeriu, à guisa de novos estudos sobre vulnerabilidade, "investigar consumidores com outros tipos de deficiências no contexto do varejo".

Em particular, enfocam-se neste trabalho os consumidores com síndrome de Down, pessoas violentamente estigmatizadas como incapazes, inúteis ou imprestáveis, e inequivocamente vulneráveis a toda sorte de preconceito, discriminação e exclusão. Nesse cenário, a presente pesquisa foi direcionada pelo objetivo principal de compreender como se revela a vulnerabilidade do consumidor com síndrome de Down em suas interações com o ambiente de mercado da cidade do Rio de Janeiro. Para buscar atingir o objetivo foram conduzidas entrevistas semiestruturadas em profundidade com 18 sujeitos Down e seus familiares, num total de 44 informantes. A coleta de dados escorou-se em narrativas de histórias de vida, descrição de fotografias e aplicação de técnicas projetivas. Conforme será explorado na seção de resultados, as entrevistas mostraram claramente a vulnerabilidade dos consumidores Down.

Este artigo está dividido em mais quatro seções além desta introdução. Na próxima seção será apresentado o referencial teórico que serviu de base para a investigação. A terceira revela os procedimentos metodológicos que foram seguidos na etapa empírica da pesquisa para que, na quarta seção, sejam apresentados os resultados. A última seção traz as considerações finais.

\section{REFERENCIAL TEÓRICO}

\subsection{Vulnerabilidade do consumidor: conceituação e discussão no âmbito da deficiência}

Tradicionalmente, a vulnerabilidade do consumidor pode ser definida como "um estado de impotência que emerge de um desequilíbrio nas interações ocorridas no ambiente de mercado ou a partir do consumo de produtos e mensagens mercadológicas" (BAKER; GENTRY; RITTENBURG, 2005, p. 134, tradução livre). Carneiro, Bellini e Pereira (2014, p. 5) designam como vulneráveis os consumidores "mais suscetíveis a sofrerem dano econômico, físico ou psicológico, ou como resultado de transações econômicas" devido a características que limitam sua capacidade de tomar decisões no mercado visando maximizar sua utilidade e seu bem-estar.

No parecer de Elms e Tinson (2012), a vulnerabilidade do consumidor denota um fenômeno complexo cujo tratamento hegemonicamente tem relacionado o termo com a ideia de consumidores negligenciados ou em desvantagem no mercado, enfocando variáveis como renda, raça, gênero e mobilidade, as quais resultam na exclusão de algumas pessoas no que tange à sua participação em atividades relacionadas ao consumo. Entretanto, os autores alertam para o fato de que, se as desigualdades econômicas e as circunstâncias espaciais podem ensejar a vulnerabilidade do consumidor, também por meio de normas e convenções sociais pode-se suscitar a vulnerabilidade, pois tais instâncias podem minar a capacidade de uma pessoa fazer valer seus direitos como consumidor.

A despeito do conforto e da segurança que os ambientes de mercado provêm para bilhões de pessoas, organizações e profissionais de marketing têm sido acusados - muitas vezes com razão, segundo Shultz e Holbrook (2009) - de explorar consumidores em geral e de tirar vantagens de alguns deles em particular, configurando-se uma íntima relação entre vulnerabilidade e oportunismo. A vulnerabilidade é igualmente associada por Diniz, Pereira e Bellini (2014) a questões de fragilidade do consumidor, de exiguidade de conhecimento quando o sujeito realiza uma transação, ou, ainda, a situações em que a pessoa pode estar desamparada em seu círculo familiar ou comunitário - circunstâncias que, frequentemente, independem de classe social.

Destarte, a vulnerabilidade do consumidor pode ser divisada como uma experiência fluida 
por entre contextos - que podem abranger fenômenos particulares, como a doença ou a deficiência, mas podem cingir aspectos geográficos e demográficos e acomodar a hodierna concepção da cultura de consumo (HAMILTON; DUNNETT; PIACENTINI, 2015).

Mason e Baker (2014) caracterizam então a vulnerabilidade no consumo como um estado existencial marcado pela impotência e falta de controle diante das condições sociais, culturais e/ou econômicas impostas pelo mercado. Para Baker, Gentry e Rittenburg (2005), trata-se de um fenômeno de curta duração que não configura uma situação estacionária para a maior parte dos consumidores. Não obstante, Shultz e Holbrook (2009) questionam se, ao invés de eventualmente qualificar uma disfunção nas relações de mercado, a vulnerabilidade do consumidor não seria somente mais um doloroso artefato do sistema capitalista, ou mais um dentre os jogos de soma zero que tipificam o sistema socioeconômico.

De todo modo, Woodliffe (2004) assevera que a vulnerabilidade do consumidor precisa ser encarada sob a perspectiva de que nem todos são iguais perante o mercado, enquanto Mansfield e Pinto (2008) afiançam que a vulnerabilidade pode se impor como duradoura para consumidores que apresentam certas características: (i) dificuldade ou impedimento de navegar pelos ambientes de mercado; (ii) acesso reduzido a bens e serviços; (iii) fragilidade ou debilidade física; ou (iv) incapacidade de compreender adequadamente comunicações fraudulentas ou mensagens publicitárias. Como se verá adiante, pessoas com síndrome de Down podem ser acomodadas em todos os quesitos antes discriminados.

Em acordo com Mason e Pavia (2014), quando se aborda a vulnerabilidade no consumo, é usual considerar vulnerável um indivíduo com capacidade limitada de se engajar efetivamente em relações de mercado. Essa vulnerabilidade pode advir de uma ampla gama de fatores pessoais e externos, mas o corpo e a saúde de um indivíduo podem ser catalisadores fundamentais para que alguém experimente a vulnerabilidade. As autoras ponderam que é por meio do corpo - esteja ele saudável ou desafiado por alguma condição de doença, idade avançada ou deficiência - que um indivíduo se engaja em práticas de consumo e construção identitária, as quais ocorrem em um ambiente de mercado dinâmico e estruturado a partir de processos e normas sociais capazes de potencializar a vulnerabilidade.

Conquanto PCD sejam assinaladas pela literatura como "potencialmente vulneráveis", Silva, Abreu e Mano (2015, p. 1) constatam que a vulnerabilidade desses consumidores, amiúde, não provém de sua deficiência, mas antes decorre "da falta de consciência, conhecimento sobre acessibilidade, bem como de atitudes antiéticas por parte das organizações". Acatando-se a premissa de que a vulnerabilidade do consumidor precisa ser historicamente escrutada (HILHORST; BANKOFF, 2004), deve-se evocar o fato de que, durante muito tempo, deficiência foi concatenada com inferioridade, principalmente sob a égide do modelo médico, por meio do qual se entende a deficiência como um problema individual, ao invés de uma questão sociopolítica. A partir do modelo social da deficiência (BRICHER, 2000; COX-WHITE; BOXALL, 2008), pode-se ponderar que a própria sociedade cria problemas para sujeitos tidos como deficientes, colocando-os em desvantagem em ambientes sociotécnicos restritivos e discriminatórios, situação acentuada precipuamente quando se trata dos deficientes intelectuais (CAVALCANTE, 2011).

\subsection{Pessoas com síndrome de Down: caracterização, estigma e inadequação ao consumo}

A síndrome de Down se configura como uma cromossomopatia, isto é, uma condição genética cujo quadro clínico global se deve a um 
desequilíbrio na constituição cromossômica: ao invés de uma duplicação do material genético, ocorre uma alteração na divisão cromossômica usual, resultando numa triplicação do par 21 (CAVALCANTE, 2011). A trissomia do cromossomo 21 altera todas as células do indivíduo e todos os sistemas, em especial o sistema nervoso, que apresenta anormalidades estruturais e funcionais, as quais acarretam disfunções cognitivas tais como rebaixamento nas habilidades de análise e síntese, fala comprometida, dificuldades em selecionar e direcionar estímulos externos, limitações na capacidade de correlação e análise, bem como problemas com atenção, memória e abstração (SILVA; KLEINHANS, 2006).

Além dos atrasos no desenvolvimento mental e do comprometimento intelectual, presentes em $100 \%$ dos indivíduos com síndrome de Down (PACANARO; SANTOS; SUEHIRO, 2008), outros problemas de saúde são recorrentes nessas pessoas, conforme Moreira, El-Hani e Gusmão (2000): cardiopatia congênita (40\% dos casos); hipotonia (100\%); problemas de audição (50 a 70\%); problemas de visão (15 a 50\%); alterações na coluna cervical (1 a $10 \%)$; distúrbios da tireoide (15\%); problemas neurológicos (5 a 10\%); obesidade e envelhecimento precoce. Recentemente, os dados de cardiopatia congênita foram atualizados para o contexto nacional - tal condição afeta 55,8\% das pessoas com síndrome de Down do sexo masculino e 44,5\% das brasileiras Down (BERMUDEZ et al., 2015).

O desenvolvimento psicomotor dos indivíduos Down costuma ser comprometido pela hipotonia, caracterizada por flacidez muscular e hiperfrouxidão ligamentar (ÁVILA et al., 2011), as quais provocam lentidão na motricidade e atraso na aquisição dos padrões motores fundamentais. Outras características fenotípicas responsáveis por uma fácil identificação dos indivíduos com síndrome de Down - e por mobilizar os estereótipos correspondentes - são olhos oblíquos, microcefalia, boca pequena, altura inferior à média e tendência ao sobrepeso (EPSTEIN, 2002; PACANARO; SANTOS; SUEHIRO, 2008).

Thomson, Ward e Wishart (1995) ponderam que a estereotipagem de pessoas com síndrome de Down como submissas e complacentes contribui para que elas permaneçam desassistidas em suas demandas. A perspectiva de incluir pessoas Down em todos os aspectos da vida cotidiana é desafiada por meio dos estereótipos estabelecidos pela hegemonia do conceito de "normalidade" na sociedade. As expectativas geradas por representações e atitudes negativas determinam o grau de acordo com o qual uma pessoa com síndrome de Down pode aprender, se desenvolver e, obviamente, engajar-se em práticas de consumo. Subsiste um brutal estigma, a partir do qual nem mesmo a escolha por uma mera atividade de lazer será aceita sem questionamento (SAORÍN, CORREDEIRA; RUIZ, 2012).

Aprofundando o debate acerca de estigmatização, Goffman (2008) define que os indivíduos culturalmente tipificados como "normais" são aqueles que não se afastam negativamente das expectativas da sociedade, dentre as quais está a prática do consumo. Cabe notar que a estigmatização ou a discriminação relacionada a aspectos como aparência ou habilidade física e/ou psicológica não configura, por si só, uma vulnerabilidade do consumidor, embora possa contribuir fortemente para tal processo (DAMASCENA, 2014).

Outrossim, mesmo que detenham certo poder aquisitivo - presumivelmente em função da família -, os indivíduos com deficiência intelectual encontram sérios problemas para se conformar aos parâmetros impostos pelas práticas relacionadas às trocas de mercado. Segundo Miller (2012), a inadequação ao consumo dos deficientes intelectuais está associada ao fato de as pessoas estarem constantemente julgando os traços mentais umas das outras, e é por meio desse juízo que elas se relacionam, inclusive em ambientes de compra.

Indivíduos com deficiência intelectual são classificados por Waddington (2009) como 
particularmente vulneráveis a produtos e serviços que podem causar problemas à saúde e/ou à integridade do usuário, tais como remédios que necessitam de bulas e bens eletrônicos que dependem de manuais. Varughese e Luty (2010) afirmam que o mercado precisa aprender a respeitar os direitos, as escolhas e a independência das pessoas com deficiência mental, especialmente no que se refere a incentivar sua inclusão nos ambientes de consumo, o que se torna especialmente problemático quando a deficiência acarreta uma dismorfia fisionômica e corpórea, como ocorre com as pessoas que apresentam síndrome de Down.

Um dos pilares do sistema capitalista reside no argumento de que, a partir do momento em que se concede ao cidadão liberdade de escolha com relação ao consumo, concede-se poder a tal sujeito, então tornado membro de uma sociedade de consumo. No entanto, em consonância com McClimens e Hyde (2012), no caso das pessoas com deficiência intelectual, essa escolha se restringe ao que fazer dentro do ambiente da casa, pois, da porta da rua para fora, parece não haver escolha alguma a ser empreendida.

\section{PROCEDIMENTOS METODOLÓGICOS}

Primeiramente é preciso destacar que esta investigação está cadastrada na Plataforma Brasil, tendo sido aprovada como parte de um projeto maior pelo comitê de ética da instituição federal de ensino superior a que um dos pesquisadores pertence. Ainda no que diz respeito à preocupação com questões éticas, teve-se o cuidado de consultar a Sociedade de Síndrome de Down em todas as etapas da pesquisa.

Em consonância com Woodliffe (2004), a investigação da vulnerabilidade do consumidor deve considerar diferenças individuais, discernir as características de cada contexto de consumo e reconhecer que nem todos os sujeitos vivenciam a vulnerabilidade do mesmo modo, o que naturalmente remete às abordagens qualitativas de pesquisa. Hamilton, Dunnett e Piacentini (2015) recomendam a precedência dos protocolos qualitativos no estudo da vulnerabilidade do consumidor, por meio de métodos múltiplos de coleta de dados.

Por sua vez, Faria e Carvalho (2013) advogam que, para o avanço das pesquisas sobre PcD, é necessário empreender estudos que incluam a participação dessas pessoas na etapa empírica da pesquisa. Dessa forma, 18 indivíduos com síndrome de Down, com idades entre 17 e 53 anos, moradores das zonas sul e oeste da cidade do Rio de Janeiro, foram validados como sujeitos de pesquisa, conquanto tenham sido também entrevistados membros de suas famílias, notadamente mães e irmãos. Vash (1988) defende que os familiares de PCD experimentam a deficiência de forma tão próxima que são capazes de fornecer informações precisas sobre os processos de exclusão sofridos pelos deficientes. Os sujeitos com síndrome de Down foram aqui identificados por meio dos codinomes I01 (Informante 01) a I18 (Informante 18). Analogamente, as 17 mães entrevistadas receberam os codinomes 119 a 135, enquanto os irmãos são os informantes 136 a 144, perfazendo um total de 44 sujeitos.

A principal técnica de exação de dados utilizada com os sujeitos foi a entrevista semiestruturada em profundidade (MALHOTRA, 2006), aplicada às pessoas com deficiência e suas famílias. As entrevistas - nas quais foram ouvidos mães, irmãos e Downs separadamente, quando possível - compreenderam três instâncias: (i) narrativas da história de vida dos deficientes e das famílias; (ii) apresentação e descrição de fotografias, procedimento nomeado "álbum de família"; e (iii) aplicação de técnicas projetivas.

Atkinson (2001) define entrevista de história de vida como um relato guiado no qual o sujeito discorre sobre sua vida, pontuando os episódios que ele julga que o entrevistador deve conhecer. Nas 
palavras de Laville e Dionne (1999, p. 158) "história ou narrativa de vida pode ser definida como a narração, por uma pessoa, de sua experiência vivida". Tendo utilizado narrativas de histórias de vida em pesquisa com foco em pessoas com deficiência mental, Glat (2009) defende que, por meio desses relatos individuais, é possível caracterizar a prática social, visto que essas narrativas trazem à luz direta ou indiretamente certa quantidade de valores, definições e atitudes do grupo no qual a pessoa se inscreve.

A técnica do "álbum de família" consiste em uma entrevista narrativa com o uso de fotografias, que tem por objetivo estimular o informante a contar uma história sobre acontecimentos importantes de sua vida e do contexto social envolvido (JOVCHELOVITCH; BAUER, 2002). No que tange a pesquisas com foco em PcD, Silva e Santos (2009), por exemplo, utilizaram álbuns de família para investigar mães de pessoas com deficiência mental. Nesta investigação, foram utilizadas fotografias das famílias pesquisadas que retratassem o convívio familiar e que, de preferência, guardassem relação com alguma situação de consumo.

Pesquisadores em marketing tomaram emprestadas as técnicas projetivas da psicologia clínica e da psicanálise e logo se deram conta de que tais métodos permitem contornar as defesas conscientes do consumidor para acessar informações de outro modo indisponíveis (DONOGHUE, 2000; BODDY, 2005). Respostas a esse procedimento podem ser interpretadas como indicativos da visão que o indivíduo tem do mundo, de seus sentimentos e de seus valores (GIL, 2008).

O material empírico obtido com as entrevistas foi tratado por meio da técnica de análise de conteúdo (BAUER, 2002; BARDIN, 2011), seguindo três procedimentos: leitura crítica; exame e avaliação do conteúdo dos trechos selecionados; e classificação de termos e ideias. Com base na posição de Laville e Dionne (1999), foram dispensados os softwares de análise de conteúdo, e optou-se por um modelo aberto de definição das categorias de análise, permitindo-se que os padrões tomassem forma no transcurso da exploração (BARDIN, 2011).

\section{REPRESENTAÇÃO DOS RESULTADOS}

\subsection{Vulnerabilidade em movimento}

Um dos fatores mais evidentes da vulnerabilidade do consumidor com síndrome de Down nas falas dos informantes remete à mobilidade urbana, conceito que pressupõe que, numa cidade, todos os meios de transporte devem funcionar de modo integrado e precisam ser acessíveis a todas as pessoas, além de requerer que o usuário desfrute dos ambientes sem receber tratamento discriminatório por suas características físicas ou intelectuais (AGUIAR, 2010). Para Castell (2008), a mobilidade urbana constitui um tema a ser explorado em estudos acadêmicos com foco em pessoas com deficiência intelectual, visto que, de forma geral, tais sujeitos tendem a apresentar mais problemas relativos à motricidade do que pessoas sem deficiência. Adicionalmente, as pessoas com síndrome de Down também parecem ter que enfrentar barreiras atitudinais que acabam prejudicando sua mobilidade, geralmente por conta do despreparo dos prestadores de serviços que trabalham com transporte (CROSIER; HANDFORD, 2012).

No que diz respeito à relação entre mobilidade urbana e consumo, Bromley, Matthews e Thomas (2007) denunciam que a dificuldade que PcD têm para se locomover nos centros urbanos faz com que elas não estejam aptas a exercer o papel de consumidores. Com respeito aos sujeitos Down, alguns entrevistados enfatizaram que o caos na mobilidade urbana reforça a impossibilidade de esses indivíduos serem consumidores autônomos, pois são impedidos de dirigirem-se aos locais de consumo por si próprios. O consumo nas imediações da residência foi apontado por mães e 
irmãos entrevistados como única alternativa minimamente viável para um sujeito Down exercer de maneira autônoma o papel de comprador. " $A$ rua, o trânsito, os carros não respeitando o sinal, tudo isso impede que ele possa ser um comprador normal" (I28).

O consumo de serviços de lazer por parte das pessoas com Down pode ser muito afetado pela falta de mobilidade urbana. Devido às dificuldades para chegar aos locais de consumo, não raramente a família inteira acaba descartando a possibilidade de se engajar na atividade escolhida pelo membro Down, caracterizando uma situação de vulnerabilidade que se amplia para toda a família, impedida de navegar livremente pelo ambiente de mercado. "Ele queria muito [ir ao cinema], mas é bem complicado levar. Precisa de todo um esquema... Mas vou levar... É difícil, limita muito mesmo" (122).

A falta de investimentos em acessibilidade e mobilidade urbana foi abordada pelas mães dos sujeitos Down como um fato que jamais será modificado. As informantes não creem que qualquer providência será tomada pelos governantes no sentido de tentar minimizar as barreiras diariamente enfrentadas pelos deficientes para se locomover nas grandes cidades.

A cidade não é preparada para eles. Os ônibus são altos, o motorista não espera. As calçadas são um horror [...] mesmo que o Down saiba andar sozinho, digo, saiba para que lado deve andar, ou ver o sinal, é difícil. Não anda sozinho, é perigoso. Aí são totalmente dependentes. O que a gente faz é que ele só anda comigo. (133)

Os principais entraves à mobilidade apontados pelos informantes - potencializadores da vulnerabilidade dos sujeitos Down - foram as condições precárias dos meios de transporte e a falta de empatia dos motoristas. Uma das mães confidenciou que, por duas vezes, desesperou-se ao imaginar que seu filho havia desaparecido, em dias nos quais ele entrou no ônibus errado por influência de outras pessoas. Em decorrência de experiências dessa natureza, quase todos os informantes julgam ser impossível que uma pessoa com síndrome de Down aprenda a andar de transporte público - note-se que no município do Rio de Janeiro a principal alternativa de transporte é a rodoviária. Os motivos apontados para essa visão pessimista foram: as limitações cognitivas dos indivíduos Down fariam com que eles não soubessem como circular na cidade; os motoristas de ônibus têm má vontade com PcD, arrancam com seus veículos e dão freadas bruscas propositadamente; os cobradores de ônibus sempre são desonestos; e passageiros mal-intencionados podem enganar o sujeito Down. "Sabemos que tem vários perigos, e carros que não param no sinal, de buracos no meio do caminho e até mesmo de pessoas com má fé" (I31).

\subsection{Para colocar a vulnerabilidade à prova}

Na categoria anterior, foram debatidas barreiras enfrentadas pelos indivíduos Down e suas famílias para chegar aos locais de compra. Contudo, quando os obstáculos são transpostos e as pessoas chegam a esses lugares, as dificuldades continuam. A esse respeito, recorrendo à expressão shopmobility, Gant (2002) defende ser necessário que qualquer pessoa tenha livre circulação nos ambientes de consumo. Os achados desta pesquisa mostraram que as situações vivenciadas cotidianamente pelos sujeitos Down e por suas famílias desencorajam a crença na real existência de shopmobility; por conseguinte, a vulnerabilidade de tais consumidores é avultada.

Primeiramente, cabe destacar os problemas de acessibilidade causados por aspectos físicos dos ambientes de compra, amplamente mencionados em estudos anteriores (CROSIER; HANDFORD, 2012). Alguns indivíduos Down confessaram sentir-se mal em ambientes apertados ou com muitas mercadorias. Segundo os respondentes, nessas situações, suas dificuldades motoras e cognitivas 
são ressaltadas, eles se sentem mais vulneráveis e acabam desistindo de permanecer no local. "Eu tinha pavor de ir na C\&A, Lojas Americanas, que têm aqueles negócios, aquelas araras ali, eu tinha um medo de [116] se enfiar ali por dentro daquelas roupas e nunca mais ninguém achar" (I20).

O cuidado com o ambiente físico de loja é importante para que se tente incluir os sujeitos Down como consumidores, mas são as atitudes dos prestadores de serviços que acabam definitivamente com essa possibilidade. A análise mostrou que numerosas interações entre os consumidores Down e os vendedores são marcadas pelo preconceito de que o deficiente não deveria estar em um ambiente de compra. Sua situação de vulnerabilidade principia pela percepção de que sua mera presença naquele ambiente é imprópria. "Temos vendedores muito despreparados. [...] em outros países os vendedores sabem lidar com a diversidade. Aqui, parece que eles ficam empurrando um para o outro, e ninguém quer atender" (I33).

Os motivos apontados para tentar explicar a falta de empatia dos atendentes com os consumidores Down variaram desde o simples desconhecimento das habilidades e limitações dessas pessoas até claros indicativos de má índole por parte de vendedores e outros funcionários. A justificativa mais recorrente, entretanto, foi a de que uma pessoa com síndrome de Down não costuma ser vista como um consumidor potencial pelo vendedor porque não trabalha e, consequentemente, não tem dinheiro. Tem-se aqui, portanto, a perspectiva de que um consumidor com deficiência intelectual apresenta vulnerabilidades semelhantes às dos consumidores desprovidos de renda (MILLER, 2012). Varughese e Luty (2010) argumentam que o mercado precisa aprender a respeitar a independência das pessoas com deficiência mental, para que então se possa pensar em inclusão.

Logo, logo, os vendedores iam querer que ele saísse da loja. Quem não tem dinheiro não é bem visto em loja. Imagina um deficiente, seria expulso gentilmente. Ela chegaria perto e perguntaria porque ele está ali. Como um corpo estranho. Nunca tentaria vender nada para ele. (I30)

Tantas dificuldades fazem muitas famílias se conformarem com o fato de que o membro Down não participe efetivamente das decisões de consumo, nem mesmo frequente os ambientes de compra. Essa ausência, por sua vez, impede que esses indivíduos aprendam a se comportar como espera é esperado nesses ambientes, reforçando, assim, por inexperiência, sua vulnerabilidade às convenções que emergem nas interações com o mercado. "Nós, normais, sabemos como é o comportamento de uma pessoa em uma loja. O Down a princípio não sabe, vai mexer em tudo e tal. Tem que levar ele várias vezes, para ele ver o funcionamento de como interagir" (I20).

O depoimento mostrado a seguir foi concedido como resposta a um exercício projetivo que descrevia a situação do indivíduo Down entrando sozinho em uma loja. Lamentavelmente, em outros depoimentos também apareceu a possibilidade de os vendedores tentarem enganar um consumidor Down que se aventura a comprar sozinho.

[A vendedora] pede para que uma amiga substitua ela no atendimento [ao Down]. A amiga diz que também não sabe atender, mas vai lá e pergunta onde está a mãe da menina. A menina diz que está sozinha, e então as duas vendedoras dizem para ela voltar outro dia com a mãe. Outra opção mais cruel é as vendedoras atenderem e venderem para ela as peças encalhadas da loja. (I39)

A possibilidade de ludibriar os indivíduos Down com base no senso comum de que eles são consumidores frágeis e despreparados constitui uma faceta cruel da exclusão. Consumidores vulneráveis deveriam receber tratamento diferenciado, embora cotidianamente prevaleça o contrário. Como se mostra em seguida, um consumidor Down representa, para 
muitos agentes de mercado, uma chance de obter dinheiro de maneira fácil e desonesta.

\subsection{O preço de ser vulnerável}

Comparativamente ao restante da população, pessoas com deficiências intelectuais têm mais dificuldades em tomar decisões concernentes a questões financeiras. Em alguns casos, conforme demonstraram Mansfield e Pinto (2008), tal inaptidão se manifesta mesmo que, numa abordagem superficial, o indivíduo deficiente pareça ter familiaridade com alguns termos próprios do universo das finanças. Em função dos atrasos no desenvolvimento cognitivo e da consequente dificuldade de alfabetização apresentada por muitos deficientes mentais, os autores professam que tais cidadãos precisam ter acesso restrito a dinheiro em espécie e ser protegidos de utilizar equivocadamente cartões de crédito e outros instrumentos que facilitam transferências monetárias, como ocorre, por exemplo, no varejo digital.

De maneira ampla, três aspectos principais do mesmo problema podem ser elencados: (i) além de os indivíduos Down não ganharem seu próprio dinheiro, (ii) eles não sabem lidar com recursos financeiros ou, (iii) quando sabem operar com dinheiro, podem encontrar no ambiente de mercado pessoas aptas a ludibriá-los. De maneira geral, os sujeitos se dirigem ao mercado plenamente vulneráveis: seus recursos são providos por outrem, eles não compreendem plenamente o valor de troca das mercadorias, e muitos deles ainda apresentam dificuldades para calcular trocos. Por conseguinte, para diminuir essa vulnerabilidade e evitar que seus filhos sejam enganados, muitas famílias optam por permitir que os indivíduos com Down tenham acesso somente a quantias monetárias muito reduzidas.

Eles aprendem que têm que dar presente. Aprendem em comerciais, aprendem em novela. Se você gosta, tem que dar presente. Mas não têm dinheiro, não têm como ir até o local de compra. Enfim... isso é ruim, já vi muitos ficarem deprimidos com isso. (I24)

[Ele] compra qualquer coisa que diz que tá em promoção. Mesmo aquelas que na verdade não estão, mas que tem a plaquinha, sabe? Quer dizer, ele compraria se eu deixasse dinheiro com ele. Por essa e outras, não deixo. (126)

O problema dos roubos praticados nos ambientes de varejo foi recorrente na fala dos informantes, e não deixa de ser surpreendente constatar que quase todas as famílias entrevistadas associaram a vulnerabilidade dos indivíduos Down à facilidade com que eles podem ser logrados por vendedores, operadores de caixa e outros prestadores de serviços que, ao reconhecerem os traços típicos da síndrome naqueles consumidores, vislumbram oportunidades imediatas de explorar suas vulnerabilidades. "A mãe dá só cinco reais. Porque senão a caixa rouba ela no troco" (144). "Não tem noção de troco de dinheiro. E os outros, as outras pessoas, podem querer passar a perna também" (I36).

O comportamento criminoso de alguns agentes de mercado desencoraja muitos pais a permitirem que o filho Down realize compras sozinho. 0 depoimento mostrado a seguir foi emitido por uma das mães em reposta a um exercício projetivo que descrevia uma situação na qual um cliente Down adentra sozinho em ambiente de compra. No depoimento, a mãe deixa transparecer seu temor de que o filho seja enganado por não conhecer o valor do dinheiro, e entabula uma reflexão sobre a deficiência como uma questão social, conforme preconiza Bricher (2000). Essa constatação corrobora a afirmação de Hilhorst e Bankoff (2004), segundo a qual a vulnerabilidade do consumidor se estrutura a partir de interações no mercado.

Na hora de pagar, Maria [a vendedora] fala o dobro do preço, e o [consumidor] Down paga. Ao chegar em casa, a mãe fica triste ao ver o que o Down comprou 
uma coisa que ele nunca vai usar e que gastou mais dinheiro do que o necessário. Aí, essa mãe nunca mais vai deixar dinheiro com ele. Aí, eu te pergunto, nessa história, o que é ruim? A deficiência ou a má fé da sociedade? Deficiência é uma questão de sociedade. (I20)

A vulnerabilidade advinda da incapacidade de lidar com dinheiro ajuda a estigmatizar o indivíduo Down como eterna criança, e os próprios sujeitos afirmam comemorar quando podem pagar sozinhos por produtos ou serviços que eles mesmos escolhem, como mostra a fala da informante 108, consumidora com síndrome de Down. Já o sujeito 112, único dentre os informantes que, à época da coleta de dados, tinha emprego fixo, deixa claro que gosta de trabalhar para dispor de seu próprio dinheiro. Representando uma notável exceção entre os respondentes Down, 112 demonstrou ter boa capacidade de administrar seu dinheiro.

Naquele dia, eu fiquei feliz. Saí sem a minha mãe e paguei minha conta com meu dinheiro. (108)

Dois chopes e [vou pra] casa. Eles [colegas de trabalho] bebem mais, mas aí fica caro. Eu bebo dois, pago e vou para casa de táxi com o que sobra. (112)

Diante da falta de habilidade para lidar com dinheiro em espécie, a possibilidade de utilizar um cartão de crédito foi apontada por mães e irmãos como um grande avanço para que o consumidor Down conte com certo grau de autonomia como comprador, ainda que nem todos os sujeitos consigam valer-se desse recurso. "Você vai, compra o ingresso, sabe comprar na maquininha, passar o cartão, botar a senha, ele faz muito bem. Aí entra, vai pro cinema e se encontra, a gente se encontra depois pelo shopping, entendeu?" (123).

Adkins e Ozanne (2005) ressaltam que nem todos os deficientes intelectuais estão aptos a compreender e avaliar a complexidade associada ao uso de cartões de crédito, residindo aí um potencial significativo de que tais sujeitos sofram traumas de natureza econômica, física e/ou psicológica quando interagem nos ambientes do mercado. Mansfield e Pinto (2008), por exemplo, fornecem evidências de um expressivo número de pessoas com deficiências intelectuais que acumularam dívidas em razão de sua baixa compreensão acerca da utilização de cartões de crédito, salientando sua vulnerabilidade.

\subsection{Vulnerabilidade como invisibilidade}

Nas palavras de Hall e Kearns (2001), a invisibilidade social a que são submetidos os deficientes mentais remete à metáfora de um "asilo sem paredes", provocado pelo medo, pelo desprezo, pela repulsa ou pela indiferença dos outros membros da sociedade, mas também pelo reforço ao isolamento perpetrado por seus próprios parentes - desamparados diante de uma estrutura social que classifica o deficiente mental como um inútil, um incapaz, um estorvo, um problema a ser escondido do mundo. Transmudar o sujeito Down num ser invisível significa, porém, uma solução coletiva capaz de acerar sua vulnerabilidade.

A preocupação dos pais dos indivíduos Down de que eles passem despercebidos em diversas situações, inclusive de consumo, constitui um claro reflexo da disposição apresentada pela sociedade de manter tais pessoas na invisibilidade. As mães entrevistadas demonstraram ter consciência de que há uma vontade de negar a existência dos indivíduos Down e, por conseguinte, de não precisar lidar com suas demandas. Para Hall e Kearns (2001), diante da pressão social para que o deficiente mental seja afastado das demais pessoas, frequentemente os pais fingem crer que seus filhos Down realmente devem ser mantidos isolados.

As pessoas não querem ver [os indivíduos Down]. Eles não são o padrão nem de estética, nem de comportamento que a sociedade quer ver. (I30) 
Não convive, não chama atenção. É despercebido mesmo. E não é sem querer, é mais fácil não ver, é mais cômodo. Quando você finge que o diferente não existe, você não tem que mudar nada para se adaptar a eles. Não tem que ter transporte, não tem que cobrar governantes, não tem que vender produtos, cobrar de empresários, nada. (126)

A descrença de que os deficientes possam apresentar-se como potenciais consumidores (FARIA; SILVA; FERREIRA, 2012), assim como a vontade de outros consumidores de manter PCD afastadas em ocasiões de consumo (BURNS; PATERSON; WATSON, 2009), fazem que os indivíduos Down sejam impedidos de frequentar alguns lugares. A informante 133, por exemplo, relatou que, em uma dada ocasião, seu filho e outros sujeitos Down foram impedidos de adentrar numa exposição em um centro cultural sob a alegação de que os deficientes intelectuais iriam produzir barulho e poderiam quebrar alguma coisa. A única maneira apontada pelos informantes que, em sua opinião, poderia diminuir efetivamente as barreiras atitudinais com relação aos indivíduos Down seria o aumento de sua convivência com outras pessoas.

Não pode [...] ter vergonha. Porque as pessoas às vezes vão olhar estranho, mas se você deixar de levar nos lugares por isso, está mal. Se quiser que olhem, certo? Só assim as pessoas vão se acostumar e parar de condenar a presença dos Downs nos lugares. (I33)

Quando eclode num ambiente de mercado a barreira atitudinal caracterizada pelo desejo de manter invisível o consumidor Down, a decorrência disso pode ser uma inacessibilidade proposital. Waddington (2009), por exemplo, aponta a existência de mecanismos estruturados deliberadamente para afastar PCD de modo geral de alguns ambientes de consumo, como restaurantes e clubes noturnos. Por outro lado, quando tomba o véu da invisibilidade, e o consumidor Down é verdadeiramente acolhido, sua vulnerabilidade parece esmaecer.

Gosto daquela loja, a moça fala comigo. (109)

Bom, a comida lá nem é boa. Mas ele gosta de lá porque os garçons já conhecem ele. Assim, em outros lugares, o garçom não fala com ele. Ele gosta de falar. Gosta de escolher o próprio prato. Aí, nesse restaurante, ele chega, e é uma festa, todos vêm falar com ele. Garçons, gerente, a menina da caixa. Ele adora ela. (141)

A invisibilidade transparece principalmente nas interações dos agentes de mercado com a família do consumidor Down. Na maior parte das vezes, os vendedores dirigem-se somente à pessoa que está acompanhando a PCD, provavelmente tomando por parâmetro o julgamento de que o deficiente não é capaz de fazer suas próprias escolhas.

Por exemplo, na maior parte das vezes que eu entro com o [115] em alguma loja, o vendedor só fala comigo. Ele experimenta, a pessoa pergunta se eu gostei, eu digo "ele que tem que gostar". Não adianta. (I38)

Em restaurante [...] quase nunca ele ganha cardápio. [... . quando o garçom traz uma pizza, ele fala só comigo o sabor e, se ele pede, em geral, eles me olham para saber se pode servir. Os garçons não fazem isso nem com crianças, [...] mas com o deficiente eles fazem. (143)

A partir dessa categoria de análise, aviva-se a ideia de que toda mudança pretendida no que diz respeito à inclusão dos indivíduos Down, assim como a perspectiva de permitir que tais sujeitos sejam vistos como potenciais consumidores, passam necessariamente por mudanças no âmbito coletivo. Nesse panorama, reduzir a vulnerabilidade do consumidor envolve desvelar a deficiência enquanto construção sociocultural (COX-WHITE; BOXALL, 2008). 


\section{CONSIDERAÇÕES FINAIS}

Salvaguardando a posição de que a vulnerabilidade não pode ser considerada uma singularidade de indivíduos ou grupos, pois está inscrita em relações e processos sociais complexos (HILHORST; BANKOFF, 2004), a pesquisa foi guiada pelo objetivo de compreender como se revela a vulnerabilidade do consumidor com síndrome de Down em suas interações com o ambiente de mercado da cidade do Rio de Janeiro. Acredita-se que além de trazer um estudo para a área de marketing que pode colaborar para o avanço do conhecimento sobre consumidores com deficiência, este artigo traz como principal contribuição a possibilidade de apontar caminhos para a melhora na qualidade de vida das pessoas com Down e suas famílias.

Os resultados contemplaram quatro amplas categorias de análise. A primeira delas se relaciona aos problemas com a mobilidade urbana, os quais dificultam ou impedem que os consumidores Down naveguem pelo mercado. A segunda categoria refere-se ao ambiente sociotécnico do mercado, que inclui tanto as limitações relativas à shopmobility quanto os contratempos relativos às interações com vendedores, operadores de serviços e outros agentes. Em terceiro lugar, emergiram as adversidades referentes ao trato com o dinheiro nas trocas com o mercado. A quarta e última categoria de análise descavou confluências entre a invisibilidade do consumidor com síndrome de Down e sua vulnerabilidade.

Tomados em conjunto, esses achados sugerem que a vulnerabilidade dos consumidores com síndrome de Down no mercado reverbera sua vulnerabilidade no meio sociocultural, o que se torna mais pungente quando se ressalta que a pesquisa foi conduzida em uma cidade abalizada como amistosa e acolhedora para residentes e turistas. Que resultados poderiam emergir a partir de um ambiente de mercado sem tal vocação ou compromisso para com a inclusão da diversidade? Novos esforços de pesquisa podem ser empreendidos em contextos locais e regionais capazes de caracterizar esse contraste. Também podem ser bastante relevantes novos estudos sobre o mesmo tema que utilizem diferentes metodologias e formas de análise de dados.

Cabe assomar que a deficiência pode ser conjeturada como uma entidade socialmente construída, ao invés de uma certeza biológica (HALL; KEARNS, 2001), e que, correspondentemente, a vulnerabilidade do consumidor com síndrome de Down se estrutura a partir de suas interações com o mercado. Não se trata de um indivíduo que apresenta uma mente e um corpo naturalmente vulneráveis adentrando em um ambiente de mercado: sua vulnerabilidade emerge e toma corpo a partir dessa ingressão.

\section{REFERÊNCIAS}

ADKINS, N. R.; OZANNE, J. L. Critical consumer education: empowering the low-literate consumer. Journal of Macromarketing, Thousand Oaks, v. 25, n. 2, p. 153162, 2005.

AGUIAR, F. O. Acessibilidade relativa dos espaços urbanos para pedestres com restrições de mobilidade. 2010. $190 \mathrm{f}$. Tese (Doutorado em Engenharia de Transportes) - Escola de Engenharia de São Carlos, Universidade de São Paulo, São Carlos, 2010.
ATKINSON, R. The life story interview. In: GUBRIUM, J. F.; HOLSTEIN; J. A. (Eds.). Handbook of interview research: context \& method. Thousand Oaks: Sage, 2001. p. 121-140.

ÁVILA, D. C. C. et al. Avaliação da marcha em ambiente terrestre em indivíduos com Síndrome de Down. Fisioterapia em Movimento, Curitiba, v. 24, n. 4, p. 737-743, 2011.

BAKER, S. M.; GENTRY, J. W.; RITTENBURG, T. L. Building understanding of the domain of consumer vulnerability. 


\section{REFERÊNCIAS}

Journal of Macromarketing, Thousand Oaks, v. 25, n. 2, p. 128-139, 2005.

BARDIN, L. Análise de conteúdo. Tradução Luís Antero Reto e Augusto Pinheiro. Lisboa: Edições 70, 2011.

BAUER, M. W. A análise de conteúdo clássica: uma revisão. In: BAUER, M. W.; GASKELL, G. (Eds.). Pesquisa qualitativa com texto, imagem e som: um manual prático. Tradução Pedrinho A. Guareschi. Petrópolis: Vozes, 2002. p. $189-217$.

BERMUDEZ, B. E. B. V. et al. Down Syndrome: prevalence and distribution of congenital heart disease in Brazil. São Paulo Medical Journal, São Paulo, v. 133, n. 6, p. 521524, 2015.

BODDY, C. R. Projective techniques in market research: valueless subjectivity or insightful reality? A look at the evidence for the usefulness, reliability and validity of projective techniques in market research. International Journal of Market Research, London, v. 47, n. 3, p. 239-254, 2005.

BRICHER, G. Disabled people, health professionals and the social model of disability: can there be a research relationship? Disability \& Society, Abingdon, v. 15, n. 5, p. 781-793, 2000.

BROMLEY, R. D. F.; MATTHEWS, D. L.; THOMAS, C. J. City centre accessibility for wheelchair users: the consumer perspective and the planning implications. Cities, London, v. 24, n. 3, p. 229-241, 2007.

BURNS, N.; PATERSON, K.; WATSON, N. An inclusive outdoors? Disabled people's experiences of countryside leisure service. Leisure Studies, London, v. 28, n. 4, p. 403-417, 2009.

CARNEIRO, M. R. S.; BELLINI, C. G. P.; PEREIRA, R. C. F. Obsolescência programada e vulnerabilidade do consumidor na indústria de aparelhos de tecnologia móvel. In: ENCONTRO DA ASSOCIAÇÃO NACIONAL DE PÓSGRADUAÇÃO E PESQUISA EM ADMINISTRAÇÃO, 38., 2014, Rio de Janeiro. Anais... Rio de Janeiro: Anpad, 2014.

CASTELL, L. Building access for the intellectually disabled. Facilities, Bingley, v. 26, n. 3/4, 2008, p. 117-130.

CAVALCANTE, T. C. F. Discurso argumentativo e produção de sentidos em indivíduos com Síndrome de Down. Revista Brasileira de Educação Especial, Marília, v. 17, n. 3, p. 427-440, 2011.

COX-WHITE, B.; BOXALL, S. F. Redefining disability: maleficent, unjust and inconsistent. Journal of Medicine and Philosophy, Cary, v. 33, n. 6, p. 558-576, 2008.

CROSIER, A.; HANDFORD, A. Customer journey mapping as an advocacy tool for disabled people: a case study. Social Marketing Quarterly, Thousand Oaks, v. 18, n. 1, p. 67-76, 2012.

DAMASCENA, E. O supermercado visto de outra forma: o uso de elementos sensoriais na busca para reduzir a vulnerabilidade de consumidores com deficiência visual. In: ENCONTRO DE MARKETING DA ASSOCIAÇÃO NACIONAL DE PÓS-GRADUAÇÃO E PESQUISA EM ADMINISTRAÇÃO, 6., 2014, Gramado. Anais... Gramado: Anpad, 2014.

DINIZ, I. S. F. N.; PEREIRA, R. C. F.; BELLINI, C. G. P. Limitações digitais em adolescentes: um estudo sob a perspectiva da teoria da vulnerabilidade do consumidor. In: ENCONTRO DE MARKETING DA ASSOCIAÇÃO NACIONAL DE PÓS-GRADUAÇÃO E PESQUISA EM ADMINISTRAÇÃO, 6., 2014, Gramado. Anais... Gramado: Anpad, 2014.

DONOGHUE, S. Projective techniques in consumer research. Journal of Family Ecology and Consumer Sciences, Pretoria, v. 28, p. 47-53, 2000. 


\section{REFERÊNCIAS}

ELMS, J.; TINSON, J. Consumer vulnerability and the transformative potential of Internet shopping: an exploratory case study. Journal of Marketing Management, Abingdon, v. 28, n. 11-12, p. 1354-1376, 2012.

EPSTEIN, C. J. From Down syndrome to the "human" in "human genetics". American Journal of Human Genetics, Chicago, v. 70, n. 2, p. 300-313, 2002.

FARIA, M. D.; CARVALHO, J. L. F. S. Diretrizes para pesquisas com foco em pessoas com deficiência: um estudo bibliométrico em administração. Ciências Administrativas, Fortaleza, v. 19, n. 1, p. 35-68, 2013.

FARIA, M. D.; SILVA, J. F.; FERREIRA, J. B. The visually impaired and consumption in restaurants. International Journal of Contemporary Hospitality Management, Bradford, v. 24, p. 3-19, 2012.

GANT, R. Shopmobility at the millennium: 'Enabling' access in town centers. Journal of Transport Geography, Oxford, v. 10, n. 2, p. 123-133, 2002.

GIL, A. C. Métodos e técnicas de pesquisa social. 6. ed. São Paulo: Atlas, 2008.

GLAT, R. "Somos iguais a vocês": depoimentos de mulheres com deficiência mental. 2. ed. Rio de Janeiro: 7 Letras, 2009.

GOFFMAN, E. Estigma: notas sobre a manipulação da identidade deteriorada. Tradução Márcia Bandeira de Mello Leite Nunes. 4. ed. Rio de Janeiro: LTC, 2008.

HALL, E.; KEARNS, R. Making space for the 'intellectual' in geographies of disability. Health \& Place, Amsterdam, v. 7, n. 3, p. 237-246, 2001.

HAMILTON, K.; DUNNETT, S.; PIACENTINI, M. Introduction. In: (Eds.). Consumer vulnerability: conditions, contexts and characteristics. London: Routledge, 2015. p. 1-10.

HILHORST, D.; BANKOFF, G. Introduction: mapping vulnerability. In: BANKOFF, G.; FRERKS, G.; HILHORST, D. (Eds.). Mapping vulnerability: disasters, development \& people. London: Earthscan, 2004. p. 1-9.

IBGE - INSTITUTO BRASILEIRO DE GEOGRAFIA E ESTATíSTICA. Censo Demográfico 2010. IBGE.gov, Rio de Janeiro, 2010. Disponível em: <https://goo.gl/G4zkSU> Acesso: 12 fev. 2015.

JOVCHELOVITCH, S.; BAUER, M. W. Entrevista narrativa. In: BAUER, M. W.; GASKELL, G. (Eds.). Pesquisa qualitativa com texto, imagem e som: um manual prático. Tradução Pedrinho A. Guareschi. Petrópolis: Vozes, 2002. p. 90-113.

LAVILLE, C.; DIONNE, J. A construção do saber: manual de metodologia de pesquisa em ciências humanas. Tradução Heloísa Monteiro e Francisco Settineri. Porto Alegre: Artmed, 1999.

MALHOTRA, N. Pesquisa de marketing: uma orientação aplicada. Tradução Laura Bocco. 4. ed. Porto Alegre, Bookman, 2006.

MANSFIELD, P. M.; PINTO, M. B. Consumer vulnerability and credit card knowledge among developmentally disabled citizens. The Journal of Consumer Affairs, Malden, v. 42, n. 3, p. 425-438, 2008.

MASON, M.; BAKER, S. M. Beyond vulnerability: building resilient consumers and communities. In: ADVANCES IN CONSUMER RESEARCH, 42., 2014, Baltimore. Proceedings... Duluth: Association for Consumer Research, 2014.

MASON, M.; PAVIA, T. Health and consumer vulnerability: identity dissolution and resiliency behaviors. In: ADVANCES IN 


\section{REFERÊNCIAS}

CONSUMER RESEARCH, 42., 2014, Baltimore. Proceedings... Duluth: Association for Consumer Research, 2014.

MCCLIMENS, A.; HYDE, M. Intellectual disability, consumerism and identity: to have and have not? Journal of Intellectual Disabilities, London, v. 16, n. 2, p. 135-144, 2012.

MILLER, G. Darwin vai às compras: sexo, evolução e consumo. Tradução Elena Galdano. Rio de Janeiro: Best Business, 2012.

MOREIRA, L. M. A.; EL-HANI, C. N.; GUSMÃO, F. A. F. A síndrome de Down e sua patogênese: considerações sobre o determinismo genético. Revista Brasileira de Psiquiatria, São Paulo, v. 22, n. 2, p. 96-99, 2000.

NOVAIS, P. Urbanismo na cidade desigual: o Rio de Janeiro e os megaeventos. Revista Brasileira de Estudos Urbanos e Regionais, São Paulo, v. 16, n. 1, p. 11-33, 2014.

PACANARO, S. V.; SANTOS, A. A. A.; SUEHIRO, A. C. B. Avaliação das habilidades cognitivas e viso-motora em pessoas com Síndrome de Down. Revista Brasileira de Educação Especial, Bauru, v. 14, n. 2, p. 311-326, 2008.

ROCHA, M.; ZOUAIN, D. M. Percepção socioambiental: a visão de turistas e gestores de hotéis sobre os impactos da poluição das praias no turismo do Rio de Janeiro. Revista Brasileira de Pesquisa em Turismo, São Paulo, v. 9, n. 2, p. 360-377, 2015.

SAORÍN, J. M.; CORREDEIRA, R. M. N.; RUIZ, M. V. La percepción social hacia las personas con Síndrome de Down. Educação e Pesquisa, São Paulo, v. 38, n. 4, p. 949-964, 2012.

SHULTZ, C. J.; HOLBROOK, M. B. The paradoxical relationships between marketing and vulnerability. Journal of Public Policy \& Marketing, Chicago, v. 28, n. 1, p. 124127, 2009.
SILVA, G.; SANTOS, M. A. Álbum de família e esquizofrenia: convivência em retrato. Psicologia em Estudo, Maringá, v. 14, n. 1, p. 83-91, 2009.

SILVA, J. O.; ABREU, N. R.; MANO, R. F. Consumidores vulneráveis ou vulnerabilizados? uma reflexão sobre a acessibilidade em meios hoteleiros na ótica das pessoas com deficiência física. In: ENCONTRO DA ASSOCIAÇÃO NACIONAL DE PÓS-GRADUAÇÃO E PESQUISA EM ADMINISTRAÇÃO, 39., 2015, Belo Horizonte. Anais... Belo Horizonte: Anpad, 2015.

SILVA, M. F. M. C.; KLEINHANS, A. C. S. Processos cognitivos e plasticidade cerebral na Síndrome de Down. Revista Brasileira de Educação Especial, Bauru, v. 12, n. 1, p. 123-128, 2006.

THOMSON, G. O. B.; WARD, K. M.; WISHART, J. G. The transition to adulthood for children with Down's Syndrome. Disability \& Society, Abingdon, v. 10, n. 3, p. 325-340, 1995.

VARUGHESE, S. J.; LUTY, J. Stigmatised attitudes towards intellectual disability: a randomised crossover trial. The Psychiatrist, London, v. 34, n. 8, p. 318-322, 2010.

VASH, C. L. Enfrentando a deficiência: a manifestação, a psicologia, a reabilitação. Tradução Geraldo José de Paiva, Maria Salete Fabio Aranha, Carmen Leite Ribeiro Bueno. São Paulo: Pioneira, 1988.

WADDINGTON, L. A disabled market: free movement of goods and services in the EU and disability accessibility. European Law Journal, Oxford, v. 15, n. 5, p. 575-598, 2009.

WOODLIFFE, L. Rethinking consumer disadvantage: the importance of qualitative research. International Journal of Retail \& Distribution Management, Bradford, v. 32, n. 11, p. 523-531, 2004. 